\title{
Research on Commercial Bank Risk Early Warning Model Based on Dynamic Parameter Optimization Neural Network
}

\author{
Yiming Wang (iD \\ School of Business, Macau University of Science and Technology, Cotai, Macau \\ Correspondence should be addressed to Yiming Wang; 1709853ebm30001@student.must.edu.mo
}

Received 6 December 2021; Revised 2 January 2022; Accepted 5 January 2022; Published 4 February 2022

Academic Editor: Miaochao Chen

Copyright (C) 2022 Yiming Wang. This is an open access article distributed under the Creative Commons Attribution License, which permits unrestricted use, distribution, and reproduction in any medium, provided the original work is properly cited.

\begin{abstract}
Based on the background of big data, it is necessary to study the dynamic parameter optimization of the commercial bank risk model neural network. Several customer information attribute groups that have an impact on loan customer rating are selected, and the existing customer data are used to train the network model of the attribute group and customer default rate, so that it can predict the customer's default rate according to the newly entered loan customer information and then predict whether the customer defaults. Based on a neural network model, this article constructs the credit risk early warning model of science and technology bank, makes an empirical test, and puts forward relevant countermeasures and suggestions to control the credit risk of bank. This article establishes a warning model of commercial banks by using a neural network. Taking the bank as an empirical sample, the constructed neural network model is used. Finally, the error of the model is small and the early warning results are satisfactory. The experimental results show that the proposed risk early warning model can accurately predict the customer default rate, so as to warn the defaulting customers. In the whole process, there are few human intervention factors and a high degree of intelligence, which reduces the operational risk.
\end{abstract}

\section{Introduction}

After entering the 21st century, China has developed rapidly in the financial field. Commercial banks and other financial institutions in the financial field have been greatly enhanced in all aspects. The convenience brought to the people by commercial banks and other financial institutions in the financial field has gradually appeared in many aspects of people's life. The way that commercial banks provide personal commercial credit for individual residents to improve their lives is a very specific embodiment of the convenience to the people. Banks of commercial loans to individuals have become an effective way for individuals to maximize their consumption level. For commercial banks, increasing the volume of credit business also improves their strength. There are many management problems in this aspect, such as the selection of the credit risk early warning mechanism model. Due to the outbreak of the new coronal pneumonia virus, the financial industry has suffered a great impact. Reasonable risk control can also make the income of commercial banks more stable and planned. Therefore, the importance of credit risk management is self-evident [1-3].

Traditional risk early warning models mostly use multivariate statistical methods, logistic regression, and other models to evaluate risk, but it is difficult to use them for a large number of structural nonlinear data. Moreover, the above models rely on historical data and have poor dynamic warning efficiency, which shows great limitations in dealing with increasingly complex early warning problems. With the maturity of modern comprehensive evaluation and analysis field and the development of artificial intelligence program, the importance of establishing an multilevel and all-round credit risk early warning index system has reached a consensus in the field of risk early warning. Therefore, learn from the risk warning system and methods of banks of commercial, innovate on this basis, and build a risk warning index specially belonging to science and technology banks from the three aspects of enterprises, to reduce the credit risk of banks, improve the financing efficiency enterprises, and improve the science and technology financial system dominated by banks [4-9]. 
For the combination of financial innovation, commercial banks can not only provide financing services for enterprises, but also realize their own value-added and promote economic development. Figure 1 shows the position of commercial banks in the financial system.

As a simple practical statistical research method, linear regression is one of the earliest statistical methods used to establish a risk early warning model. Myers first introduced this method into the research of credit risk assessment. By combining the characteristic level of credit risk early warning indicators, Myers found the best combination of characteristics through linear regression. From the perspective of the impact of credit risk, due to information asymmetry, Orgler believes that using the behavior characteristics of the borrower as the explanatory variable can better increase the prediction accuracy of the model. Therefore, in the research, the linear regression method is used to evaluate the borrower's credit risk from the perspective of the borrower's information. Lachenbruch introduced dummy variables on the basis of linear regression and predicted the probability of credit default by adding dummy variables to the linear regression model, so as to achieve the effect of credit risk early warning. Fitzaptrick and Henley also continued in-depth research on this basis, using the relevant theories of mathematical statistics, continuously optimized the interpretation ability of linear equation in credit risk assessment, and continuously improved the prediction accuracy of linear equation in the model for credit risk early warning. Researchers gradually began to analyze the advantages and disadvantages of the model, and the research direction began not only to be limited to one direction or a single model. Researchers began to integrate a variety of models gradually and give full play to the advantages of each model by learning from each other. By analyzing the history of credit risk early warning and its application at home and abroad, Jiang Minghui combined the advantages of different prediction models on the basis of portfolio prediction and proved through empirical results that portfolio model has greater advantages than the single model in accuracy. By combining different models and absorbing the advantages of different models, Sun concluded that the combined model has higher prediction accuracy and stability than the single model. Khanbabaei combines the genetic algorithm with the decision tree model to obtain a new hybrid data mining method, combines the advantages of the genetic algorithm with the advantages of the decision tree model, verifies the model based on the new hybrid data mining algorithm with data, and obtains the conclusion that the new model is better than the traditional model in prediction accuracy. Based on the data of a commercial bank in Germany, Yang Shenggang combines the decision tree model with the neural network model to obtain a new personal credit risk early warning model. Firstly, the index system of the personal credit early warning model is screened through the decision tree model, and the interference of some nonimportant index factors in the index system is removed by using the entropy increase principle of the decision tree model. Combined with the neural network model, the combined model is formed. Through comparative research, the prediction accuracy is higher than the single BP neural network model. CK Leong combines the Bayesian discrimination method with the neural network model to obtain a Bayesian network model. By optimizing the truncated samples and sample imbalance of the model in credit risk assessment, the model accuracy and model sensitivity are improved [10-14].

In essence, commercial banks are also enterprises, which need to conduct capital transactions with enterprises in different industries and obtain profits. Moreover, due to the particularity that commercial banks are mainly engaged in monetary business, commercial banks need to face more complex risks than other types of enterprises. Let the commercial bank become a high-risk enterprise that wants to gather all kinds of risks in the operation of the national economy. Due to the high asset liability ratio of commercial banks, commercial banks are more willing to do some businesses with greater risks than other enterprises. Because the input and output of commercial banks are almost completed in the form of money, it also causes great harm to the national economy when commercial banks have their own risks. As an enterprise, commercial banks essentially pursue interests, which makes commercial banks have a natural tendency to pursue profits. At present, China's financial industry is facing the reform. How to grasp the opportunity and pursue the greatest interest in the wave of financial reform has become the strategic goal of major commercial banks. In order to achieve this goal, some commercial banks attract customers through more attractive conditions or lower price products. Therefore, under such a background, all commercial banks have made great articles on marketing policies, resulting in the further compression of the profit space of most commercial banks in loans. At present, the profits of China's commercial banks mainly come from the profits obtained through credit. Once the profits of commercial banks in this part are seriously received, that is, once the personal credit default risk occurs in a large area, commercial banks will face huge losses. Lower loan conditions will enable many borrowers who originally did not have the ability to repay to obtain loans. Whether these borrowers can repay the loans in the future will be a huge question mark. For commercial banks, the probability that these loans will become nonperforming loans in the future is greater than ordinary loans, and the probability of personal credit risk default of borrowers will be greater [15-18].

As a high-risk enterprise, the performance of China's commercial banks in internal risk management does not match the risks they face. From the experience at home and abroad, the internal risk management ability of commercial banks will be an important factor affecting the probability of credit risk of a commercial bank. One of the main reasons for the outbreak of the U.S. subprime mortgage crisis is that the transformed banking institutions failed to successfully cultivate the corresponding internal risk management mechanism. In China, the strategic focus of most commercial banks is mostly on performance, excessively pursuing business development and business volume, paying 


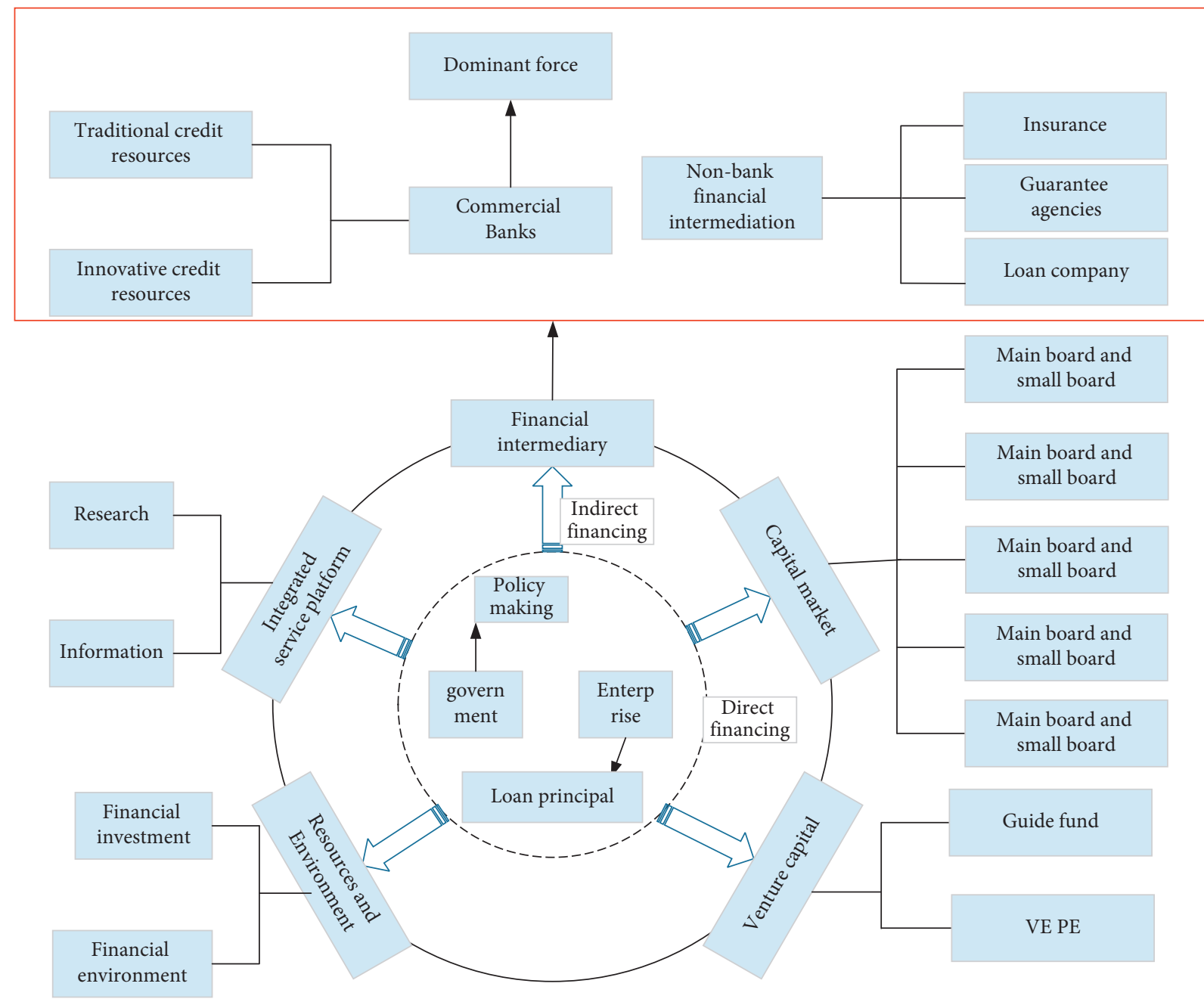

FIgURE 1: Commercial banks status.

more attention to the number of total business, and relatively ignoring the construction of an internal risk management system. At present, the internal management mechanism of credit risk in China's commercial banks is not very complete. China's commercial banks lack an effective internal management system of credit risk in internal risk management [19-24].

With the improvement of bank risk management and the development of science and technology, the development of network model and the research on bank risk early warning mainly focus on the evaluation of accuracy and risk types. Carlos Leon uses the artificial model to classify the balance sheet data of Columbia bank from 2000 to 2014 and puts forward that the financial statements of each bank are unique and representative, and the artificial neural network can identify a bank, which has high accuracy in early bank risk early warning. Hong Hanh Le et al. used two traditional statistical methods and three machine learning to compare the bankruptcy risk of 3000 American banks. The research results show that the KNN algorithm is the most accurate one. Luo Shuhao constructed the liquidity risk early warning model of Bank of
Nanjing through the function approximation characteristics and achieved good evaluation and early warning results. Zeng Rongxin predicts the credit risk for the credit customers of local corporate banks in Guizhou Province and concluded model is more accurate in the early warning of credit risk. Li Li establishes the financial risk warning system of grass-roots central banks, which provides an effective basis for financial risk evaluation and prevention [25-33].

Explore the application of neural network in credit customer risk management of banks. Select several customer information attribute groups that have an impact on the rating of loan customers and build a network model of attribute group and customer default rate, so that it can predict the default rate of the customer according to the basic attribute group of new loan customers, predict whether the loan customer defaults, reach the early warning of defaulting customers, and according to its comprehensive evaluation level, and implement different credit schemes. On this basis, banks also need to consider the impact of sudden factors on credit and make adjustments to credit strategies accordingly. 


\section{Neural Network Theory}

Neural network can learn independently. With the help of statistical knowledge and mathematical knowledge, it has learning characteristics without artificial adjustment. The input and output of the model need to maintain a certain correlation. The calculation of bank risk early warning and discrimination is complex. There is no way to directly and accurately obtain the value of risk early warning, and the input value needs to be continuously adjusted according to the output value.

The number of output layer nodes is determined abstractly by the actual problem and corresponds to the evaluation results. Therefore, it is necessary to determine the expected output first. A neural network can have multiple output variables, and the output variables support numerical variables and language variables. Considering that the network output can only be the value of $[0,1]$ interval, it is difficult to visually display the prediction results, so the output variable of this model is language variable. According to the severity of bank operation risk, the early warning level is divided into four types of early warning signals: green, blue, orange, and red. In this article, the expected output language variables of Lao Chinese bank operation risk early warning are set as four types of risk from low to high: green-safety, blue-light alarm, orange-medium alarm, and red-danger. Since there are not many expected output categories, the representation method of language variables selects the " 1 out of $n$ " methods that can intuitively reflect the results; that is, make the number of components of the output vector equal to the number of categories, take 1 for the corresponding output components according to the output samples, and take 0 for all the other $N-1$ components. To sum up, in this study, the four types of early warning signals expected to be output by the early warning model are represented by four vectors-0001, 0010, 0100, and 1000 , and then, the node number of neurons in the output layer is 4, as shown in Figure 2.

Neural network computing is a distributed processor, in which neurons are mainly connected with each other. The distributed neurons are the smallest unit of neural network computing, and the smallest unit interacts with each other for parallel computing. Neural network is used to simulate the problem, which has the ability of storage, training, and recognition. That is, the data structure, training, and recognition of connections in the network are affected by the dynamic evolution and adjustment of each neuron's connection weight.

The expression of the most commonly used function is

$$
\begin{aligned}
f(u) & =\frac{1}{1+e^{-u},} \\
u_{i}(k) & =\sum_{j=1}^{N} w_{i, j} x_{i}-\theta_{i}, \\
y_{i} & =f\left[u_{i}(k)\right] .
\end{aligned}
$$

Dynamic parameter optimization neural network realizes modeling by alternating forward and backward propagation of data flow [34-40].

For neural networks, the number of nodes in the input layer and output layer is the first parameter to be determined. In this article, standardized data of the index obtained by factor analysis is taken as input; that is, the number of nodes in the input layer is 5. Take the risk interval in which the risk warning value falls as the output; that is, there is 1 node in the output layer. Increasing the number of hidden layer nodes can enhance the processing and computing ability of the neural network to nonlinear data, so that the error can be quickly reduced to the target value. However, if there are too many nodes, the training effect will be reduced.

The learning process of the neural network can be divided into the following two steps by using the algorithm flow shown in Figure 3:

Forward propagation of working signal: take a sample $N_{m}$ from the sample set and set $\theta_{i}$ as the threshold of the $i$ neuron of the hidden layer:

$$
\begin{gathered}
Y_{m}=f\left(\sum_{i=1}^{m} w_{i h} X_{m}-\theta_{i}\right), \\
O_{j}=g\left(\sum_{j=1}^{m} w_{h j} Y_{m}-\theta_{j}\right) .
\end{gathered}
$$

The total network error is

$$
e_{(n)}=\frac{1}{2} \sum_{j=1}^{m}\left(O_{j}-d_{j}\right)^{2} .
$$

Based on the known data, the selected activation function is sigmoid function, and the function formula is as follows:

$$
\begin{aligned}
\operatorname{sigmoid}(z) & =\frac{1}{1-e^{-2}}, \\
\text { Net } & =\sum_{i=1}^{a} w_{i} x_{i} .
\end{aligned}
$$

Substitute Net into the activation function, and the activation function of the $j$ neuron is

$$
Y_{m}=\frac{1}{1+e^{-\mathrm{Net}}}-\theta_{j},
$$

where $\theta_{j}$ is the threshold value. By constantly modifying the weight value of each neuron, the most appropriate activation function can be found. Multiple neurons form a layer, and multiple layers form a network. The network can obtain the optimal convergence network through multiple training for prediction. Through known factors, credit factors need to be solved for prediction. The hidden layer structure needs to be designed. According to the Kolmogorov theorem,

$$
S=\sqrt{m n}+a .
$$

Two hidden layers are set, and the number of neurons is 15 and 12 . 


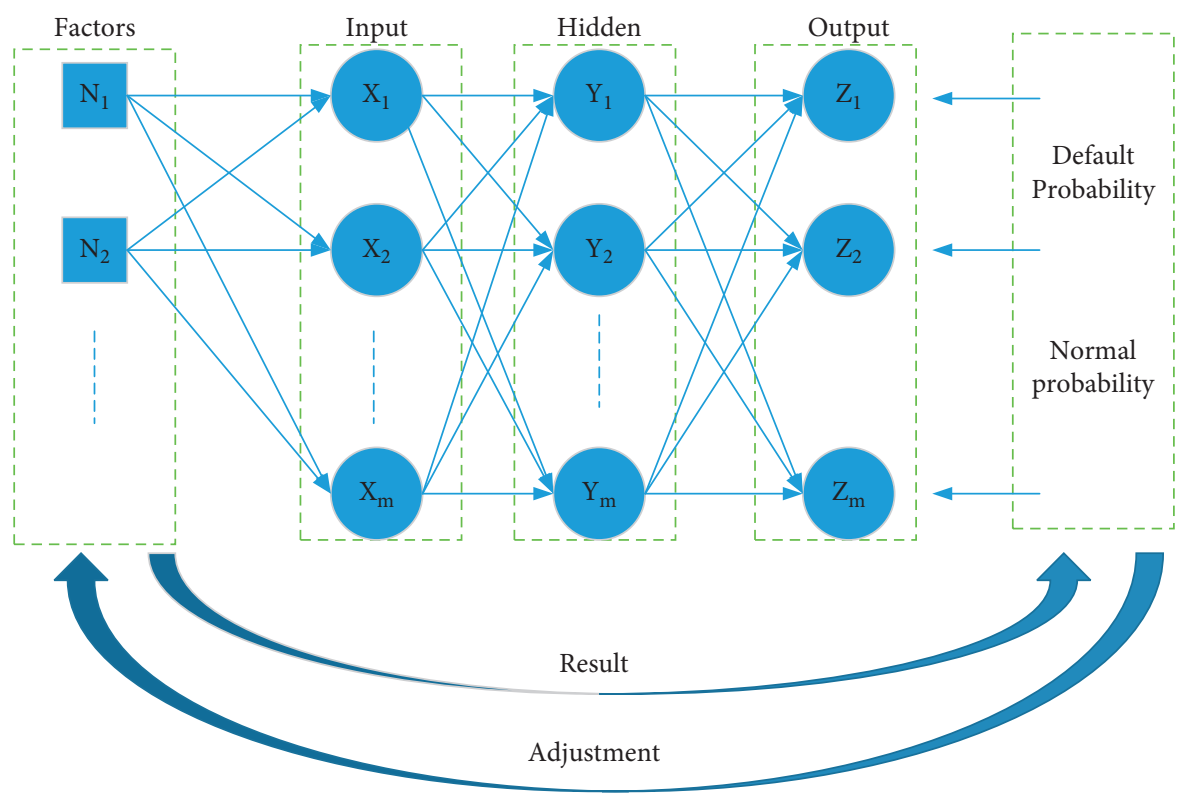

Figure 2: Topology for neural networks.

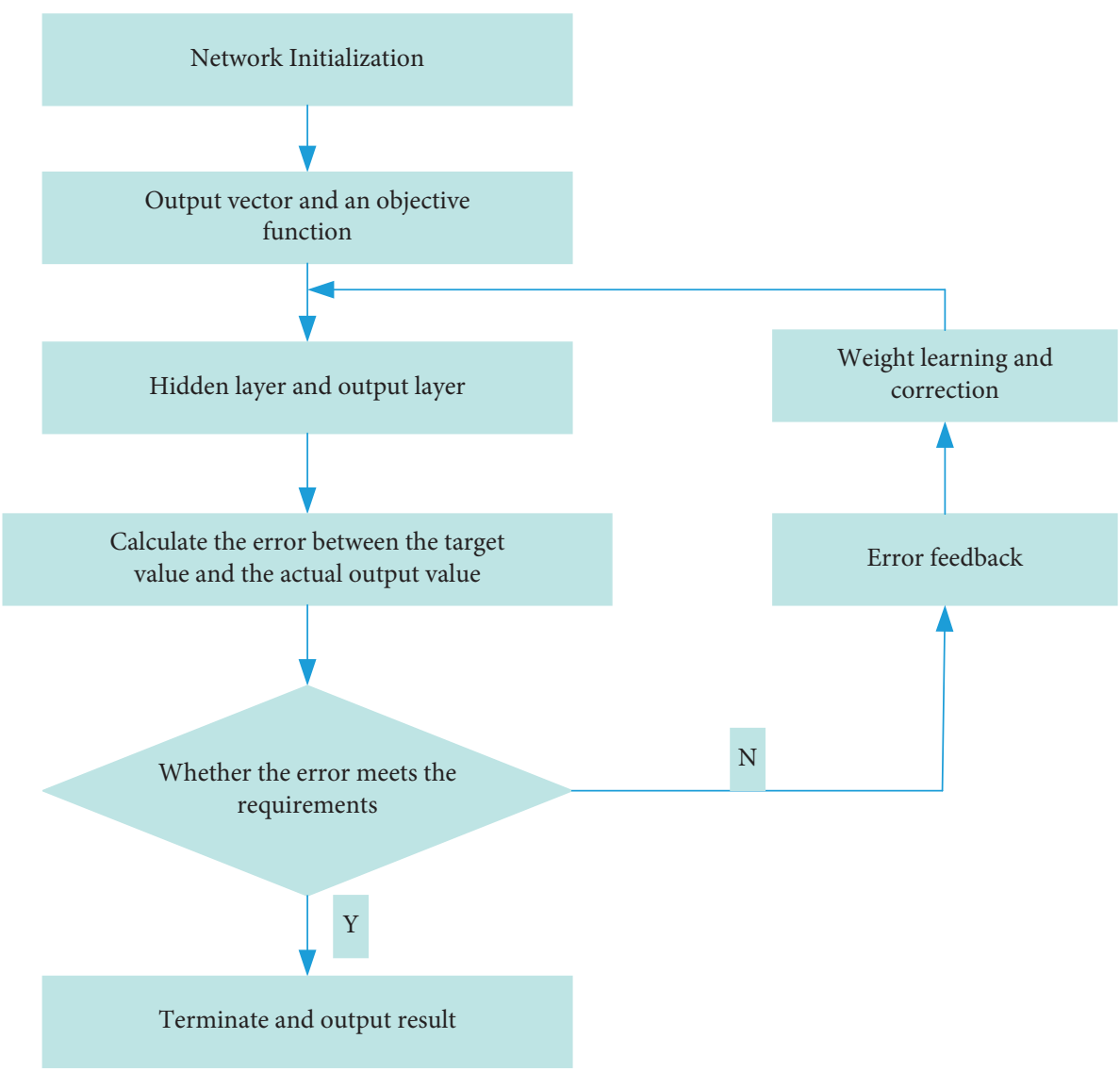

FIgURE 3: Algorithm flow.

\section{Empirical Data Sources and Processing}

On the one hand, the source of empirical data should ensure accessibility and authenticity; to ensure the training effect and fitting degree of neural network, large samples and multidata are needed to support the network. Therefore, when taking Shanghai Pudong Development Bank in Silicon Valley as an example, the five-year data from 2012 to 2016 
are selected as samples for bank indicators, and the time series data of various indicators of scientific and technological innovation enterprises from 2012 to 2016 are selected to form panel data, which meets the requirements of sufficient data volume. Get the annual report of Shanghai Pudong Development Bank on finance from China Science and Technology Statistics Yearbook report.

Because the data collected in the study are not of the same order of magnitude, the prediction error of the neural network will become larger, and even the network output value will fall into a certain range, and normal output and error feedback cannot be carried out. Therefore, this article normalized the obtained original data and eliminated the data dimension. Process the raw data into the data within the range $[-1,1]$ :

$$
y=(\max y-\min y) \frac{x-\min x}{\max x-\min x}+\min y,
$$

where $x$ and $y$ correspond to the original data sequence and the normalized data sequence, respectively, and max and min are the maximum and minimum values in the sample data, respectively. In order to facilitate the analysis and comparison of network output data values, it is necessary to make the output data and original data fall into the same range; that is, reverse normalization processing:

$$
\begin{aligned}
x & =(\max x-\min x) \frac{y-\min y}{\max y-\min y}+\min x, \\
f(x) & =\left(1+e^{-a x}\right)^{-1}, \\
f(x) & =\frac{1-e^{-x}}{1+e^{-x}}, \quad(-1<f(x)<1) .
\end{aligned}
$$

In the same initial case, by adjusting the value of a, we can find a sigmoid function with the most appropriate shape and minimize the learning times of the network.

Learning rate $\eta$ is the key factor affecting the weight adjustment $\Delta w_{i j}(n)$ of the neural network

$$
\Delta w_{i j}(n)=-\eta \frac{\partial e(n)}{\partial w_{i j}(n)} .
$$

Through the training, verification, and testing of the network, the network finally converges to the best performance state in Figure 4. Figures 5 and 6 show the network training, verification, testing and the total fitting coefficient. The fitting coefficient of network training, verification, and testing is about 0.85 , and the total fitting coefficient is 0.84286 . The regression is good, which shows that the overall neural network fitting is ideal and the test is passed.

As shown in Figure 7, from the operation results after the neural network training is completed, the results of only three samples are different from expectations, and neural network early warning results reach $85 \%$. Because the BP neural network has the defect that it is easy to fall into the local optimal solution, the network algorithm designed in this article still has room for optimization. Next, the neural network will be further optimized through dynamic parameters.

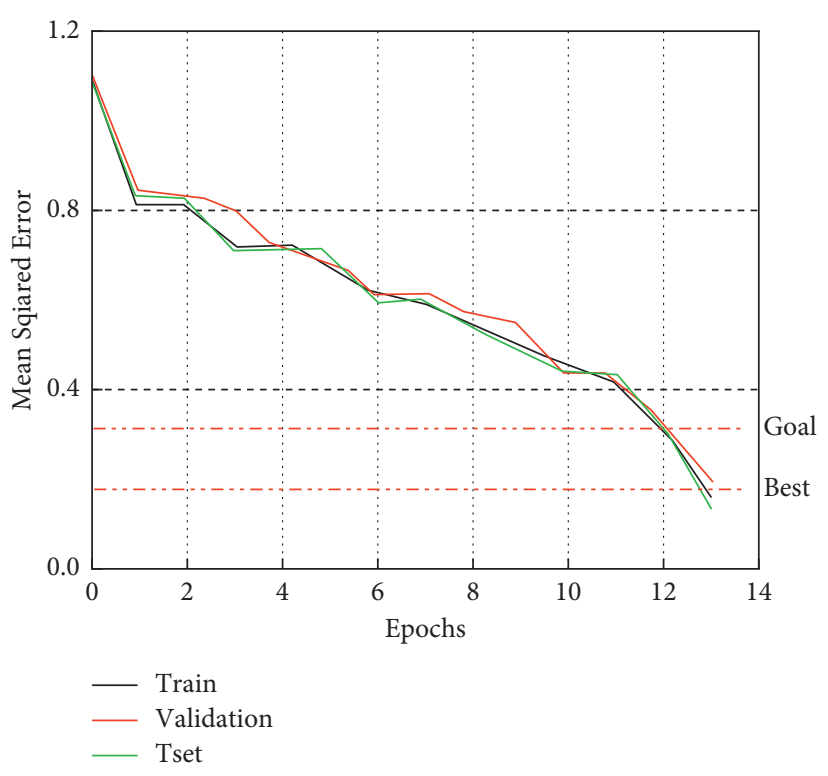

Figure 4: Training process curve.

\section{Improved Neural Network Based on Dynamic Parameters}

4.1. Introduction of Dynamic Parameter Improvement Neural Network. Dynamic variables are introduced to improve the neural network algorithm, which mainly adjusts the two dynamic parameters of weight and threshold in Figure 8. By adjusting these two parameters, the neural network and accuracy are improved. The neural network is adjusted by adjusting dynamic variables in three ways: selection, crossover, and mutation. Continuously improve the variable value to find the optimal value.

Genetic algorithm is an algorithm that simulates the mechanism of biological evolution in nature and has the characteristics of self-adaptation and direct random search. It can not only compute the optimal solution of objective function with multiple extremum points, but also search the complex solution space as an optimization algorithm. It has strong adaptive ability and robustness, and is an ideal method for solving the optimization problems of various systems for neural network operation process and results.

4.2. Analysis of Optimization Results. Neural network is an extensive parallel interconnection network composed of adaptive simple units. Its organization can simulate the interactive response of a biological nervous system to realworld objects. A neuron model is designed to simulate the structure of biological neurons. Neurons can be divided into dendrites, synapses, cell bodies, and axons. Dendrites are the input channels of neurons. It transmits the action potentials of other neurons to the cell body. The action potentials of other neurons are transmitted to the dendrites through multiple synapses located on the dendritic branches. Nerve cells can be regarded as machines with two states: "yes" when activated and "no" when not activated. When the activation conditions are met, corresponding effects will occur. 


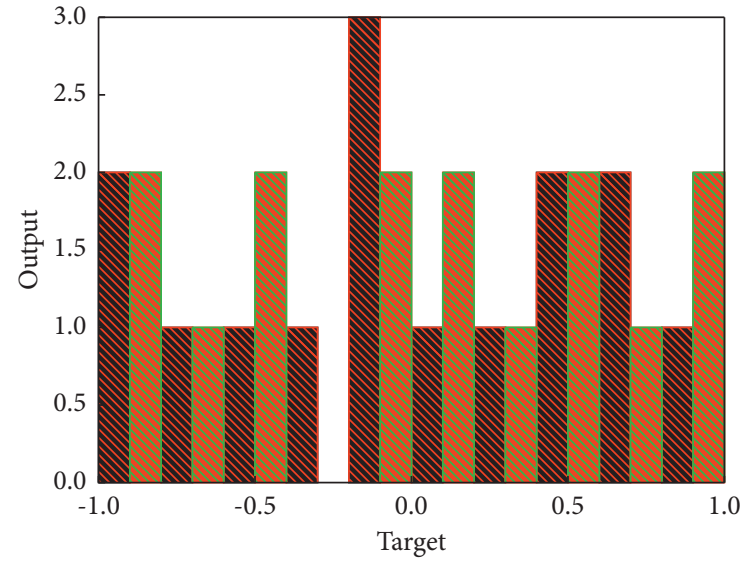

Target

Output

(a)

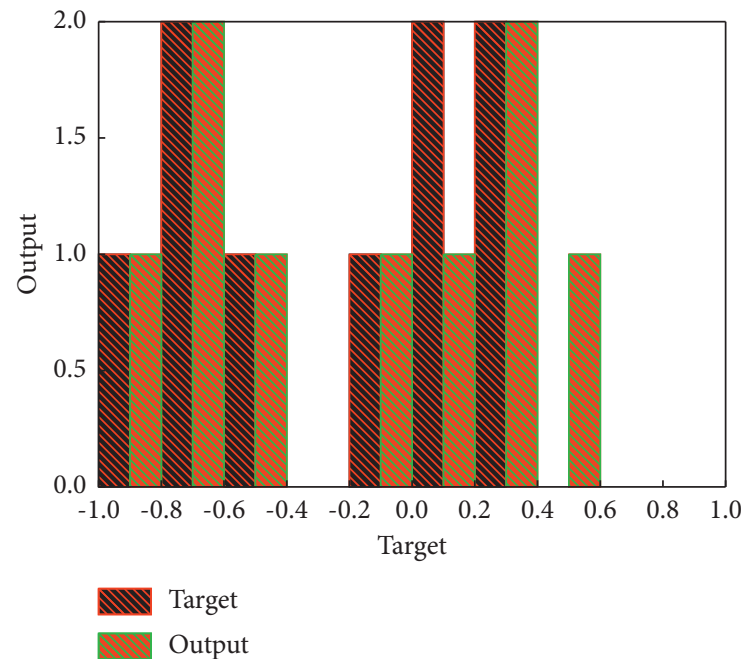

(c)

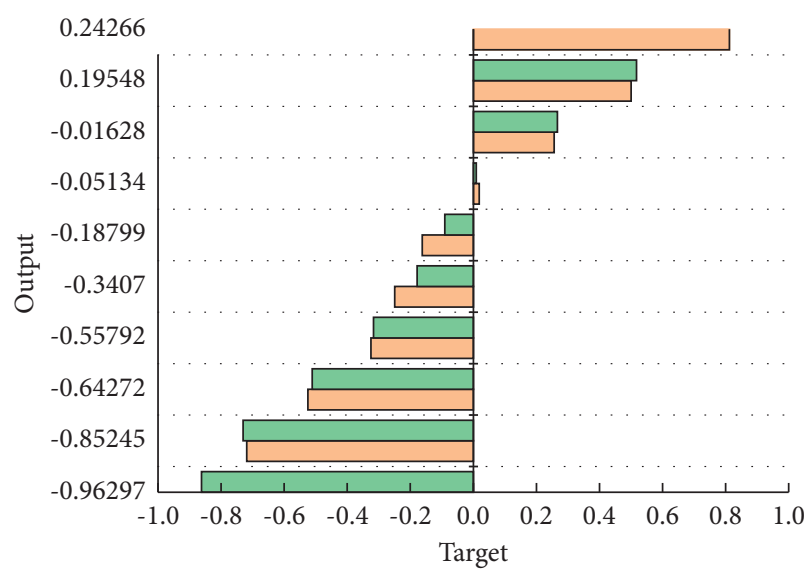

(b)

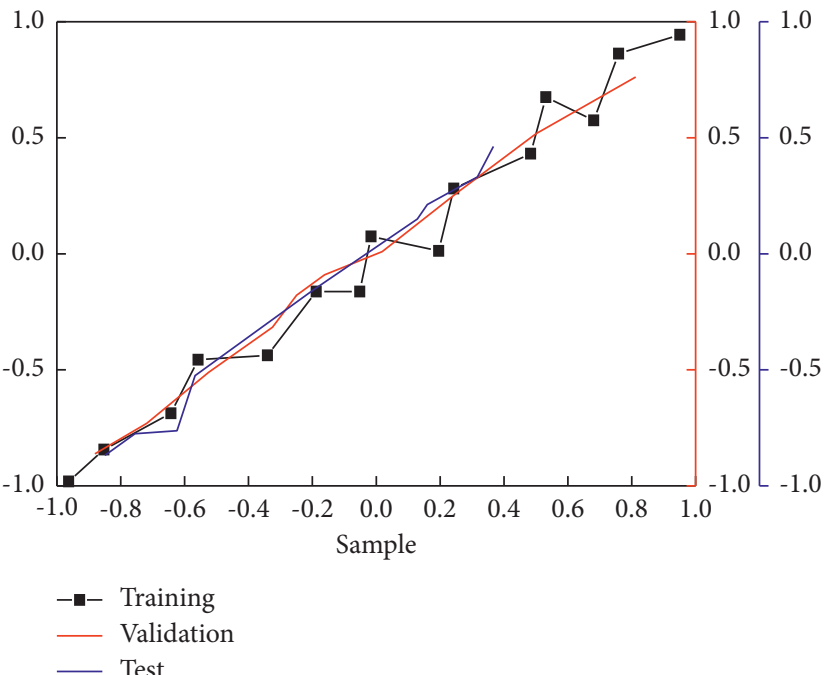

(d)

FIgure 5: Regression analysis of training. (a) Training, (b) validation, (c) test, and (d) all.

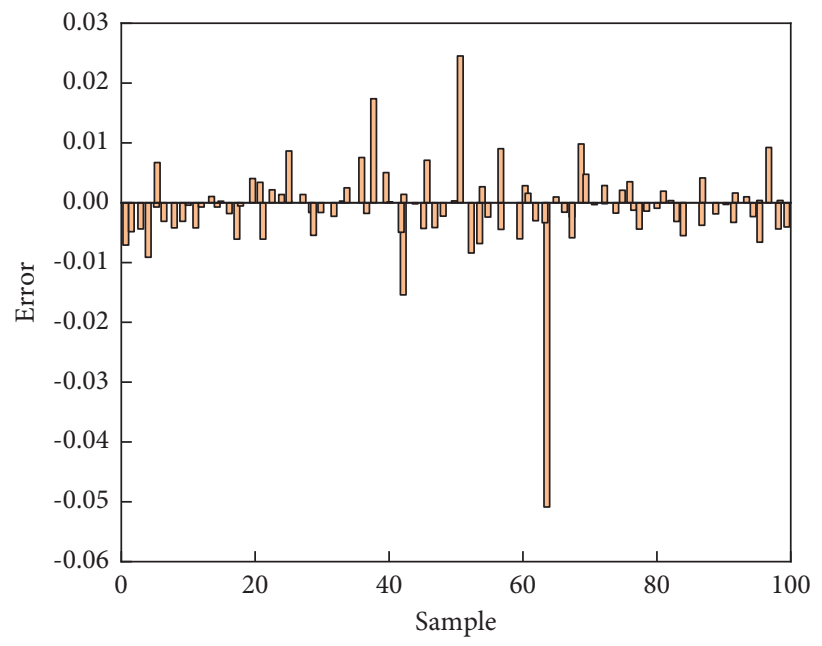

FiguRE 6: Network training error. 


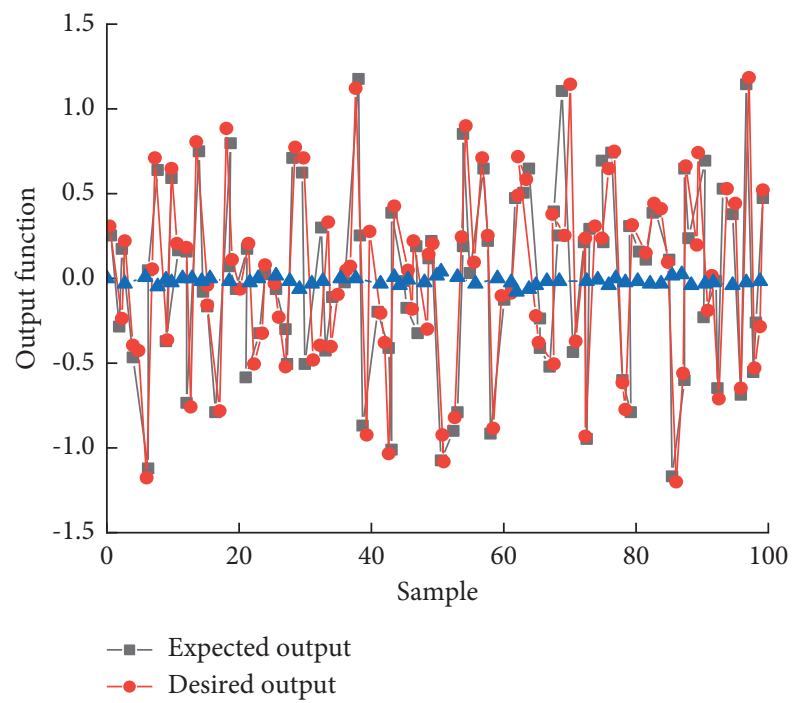

FIgURE 7: Neural network prediction output.

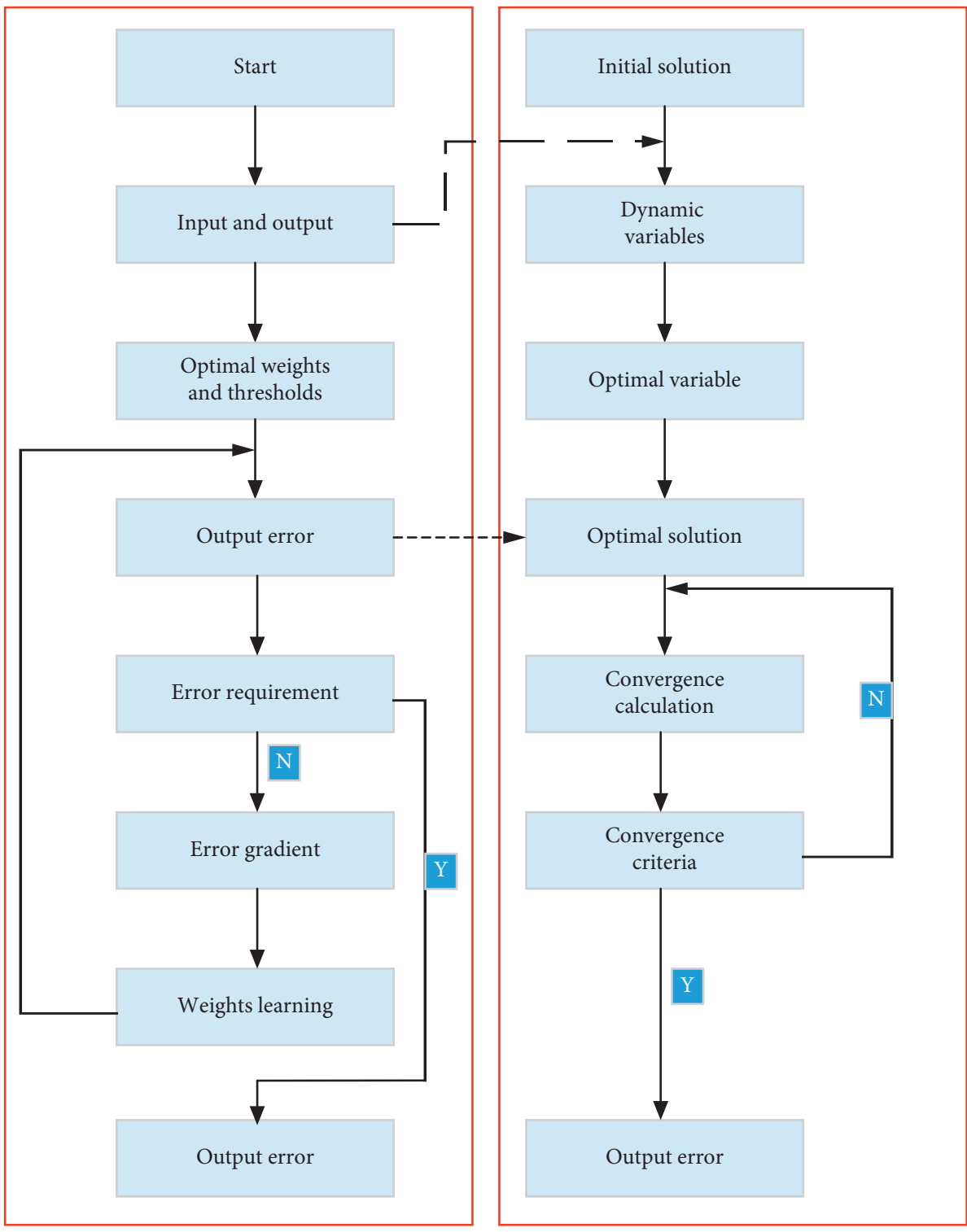

FIgUre 8: Comparative analysis calculation. 
The main evaluation indexes to measure the accuracy of the model and calculation are network error and convergence speed. Through the comparative analysis of the error and speed of the neural network before and after the improvement, the advantages, disadvantages, and applicability of the model before and after the improvement are obtained, which plays a better evaluation on the application of the model in bank early warning, as shown in Figures 9 and 10.

A total of 350 samples were randomly selected from the panel data of 90 households over 5 years as a training sample set to train the network, and the remaining 100 samples were used as test sequences to test the neural network. It can be seen that the neural network reaches convergence after iteration 13 times, and the error is reduced to the target value, and the network training is over. During the neural network training prediction, regression analysis is conducted on the samples. Figures 9 and 10 show the training process curve, regression analysis, and training error of the network. It can be seen that the fitting effect of the BP neural network is better.

4.2.1. Network Error Comparison. The evolution (iteration) times of the dynamic parameter-improved neural network algorithm is set to 100 , the crossover probability is set to 0.4 , and the mutation probability is set to 0.2 . Other parameters are the same as the previous neural network settings. The sum error of the neural network is 2.0685, the sum error of the dynamic parameter-improved neural network is 0.8739 , and the error is reduced by $55.8 \%$. The dynamic parameterimproved neural network has a smaller fluctuation range of error curve, better fitting degree with the expected results and more accurate results. By analyzing the early warning situation of 100 samples, it is found that only three samples of the dynamic parameter-improved neural network have different results from the expected results; that is, the accuracy reaches $97 \%$.

4.2.2. Convergence Rate Comparison. It can be seen from Table 1 that while reducing the network error, the dynamic parameter-improved neural network converges at the 4th training time to achieve the specified error accuracy, which is significantly higher than the convergence of an ordinary neural network at the 13th training time. At the same time, the dynamic parameter-improved neural network has shorter operation time and higher model efficiency.

The dynamic parameter-improved neural network can achieve the training target error (0.001) with smaller error gradient and fewer iterations, which can effectively avoid the neural network falling into local minimum and improve the operation efficiency.

Mean square deviation can effectively reflect the degree of calculation error, and the closer its value is to 0 , the better. According to the model training performance, the neural network model achieves the best verification performance at the 9th training. The mean square deviation of the output is 0.0023908 , and the mean square deviation value is small, indicating that the network output is more accurate and can meet the error requirements of model prediction.

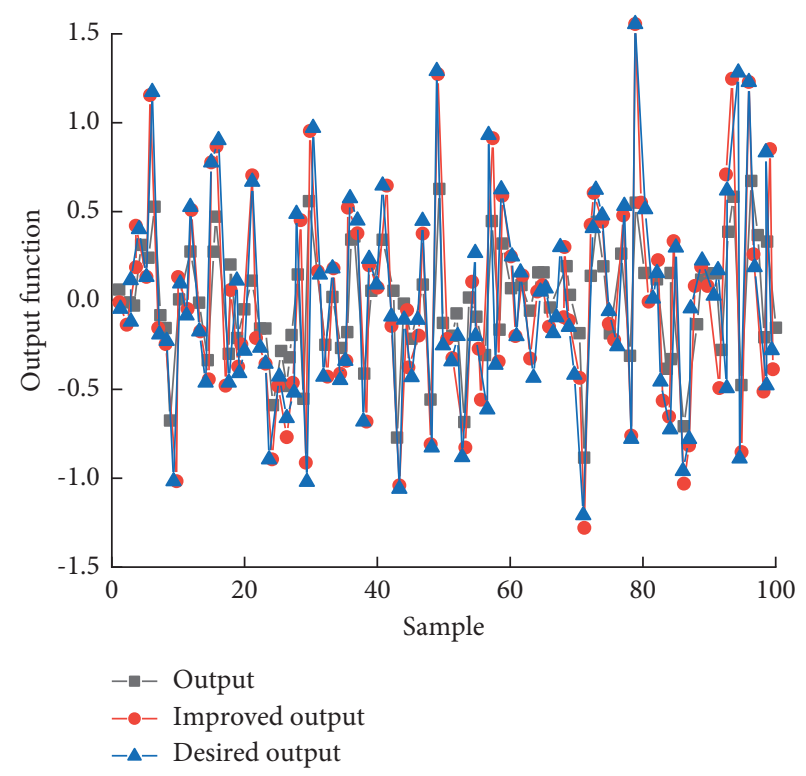

Figure 9: Outputs the comparison values.

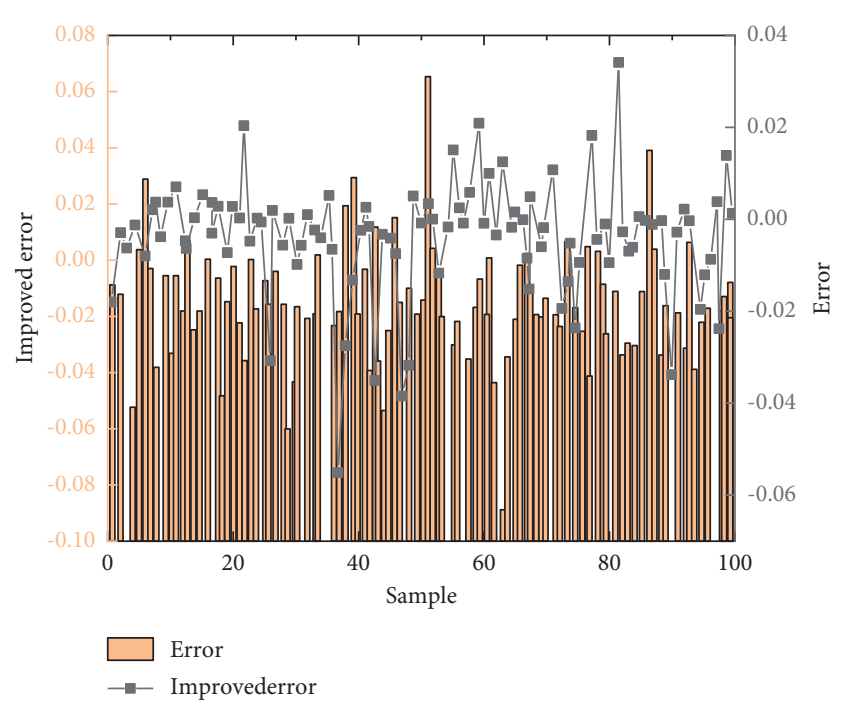

FIGURE 10: Error comparison.

TABle 1: Neural network speed comparison.

\begin{tabular}{lccc}
\hline & Iterations & Gradient & $\mathrm{ms}$ \\
\hline Neural network & 13 & 0.0307 & 10.65 \\
Improved neural network & 5 & 0.0120 & 1.76 \\
\hline
\end{tabular}

In the regression analysis of the results of the model prediction method, the goodness of fit $r$ value is usually used to reflect the linear correlation between the actual output and the expected output. The closer the $R$ value is to 1 , the better the fitting degree of the early warning model to the observed value. The total $R$ value of linear regression is 0.9988 , indicating that the established early warning model is more appropriate and the prediction results are more accurate. 
According to the above experimental results, it can be seen that the neural network model established in this study has good operability and accuracy in bank operation risk early warning, and can basically meet the needs of risk management in advance. Of course, the early warning model also has some shortcomings and needs to be improved. First, the BP neural network model has a certain dependence on experimental samples. A large number of input training and detection samples help to improve the learning and recognition ability of the neural network and achieve more accurate prediction results. However, the degree of informatization in Laos is relatively backward, the information is not accurate and transparent, and it is difficult to obtain data. In addition, the Bank of Laos and China has not been established for a long time. Although this study has collected as much data as possible through various ways, the sample data of the training group and the testing group are only six years, which will have a certain impact on the accuracy of the model prediction; second, the BP neural network needs to design many parameters, especially for the sensitivity of initial weight, and the determination of initial weight is often based on experience, which is difficult for noninformation technology professionals in model parameter maintenance and optimization; third, although the neural network is relatively easy to operate and has strong function of operation and recognition, when the amount of input data is large, the convergence speed may slow down and fall into the local optimal solution. Generally speaking, the early warning model has a relatively complete concept in the early warning of the main business risks of Laos China bank, and the prediction results are relatively accurate. The model can be further improved through continuous data collection and under the guidance of relevant technical experts.

\section{Conclusion}

(1) Neural network is used to improve and enhance the risk warning model. The empirical show that the risk warning index system proposed is reasonable, and the model with dynamic parameters used in the neural network has higher early warning accuracy. The model can be used to guide the managers of commercial banks to take risk early warning measures in advance and reduce the probability of risk occurrence, and make up for the lack of special evaluation index system. In commercial banks, it provides new ideas and methods for risk control.

(2) The mechanism of commercial banks can be established from the perspective of commercial banking business, and the risk of commercial banks can be established through the index data available in the business. Commercial banks can effectively control risks and minimize losses by establishing a long-term risk early warning mechanism.

(3) Under the basic model supporting dynamic parameters for neural network risk early warning, the commercial bank model optimization algorithm is better than commercial bank based on cross- validation method in model prediction accuracy. When using the neural network optimization algorithm for parameter selection, the accuracy is much faster than that under the cross-validation method, and the speed of finding the optimal parameter combination is greatly improved. The risk early warning model of commercial banks can have a good prediction for banks and can play an effective role in bank risk control and risk management.

\section{Data Availability}

The data used to support the findings of this study are available from the corresponding author upon request.

\section{Conflicts of Interest}

The author declares that there are no conflicts of interest.

\section{References}

[1] A. Del Ponte, P. Canofari, and A. De Dominicis, "Financial and trade relationships between the eurozone and China in the age of resilience," Asia Europe Journal, vol. 19, no. 4, pp. 489-506, 2021.

[2] J. Dong, L. Yin, X. Liu, M. Hu, X. Li, and L. Liu, "Impact of internet finance on the performance of commercial banks in China," International Review of Financial Analysis, vol. 72, no. 12, pp. 1-12, 2020.

[3] B. Zhao, K. Kenjegalieva, J. Wood, and A. Glass, "A spatial production analysis of Chinese regional banks: case of urban commercial banks," International Transactions in Operational Research, vol. 27, no. 4, pp. 2021-2044, 2019.

[4] C. Zheng, S. Chen, and Z. Dong, "Economic fluctuation, local government bond risk and risk-taking of city commercial banks," Sustainability, vol. 13, no. 17, pp. 1-26, 2021.

[5] A. G. Assaf, A. N. Berger, R. A. Roman, and M. G. Tsionas, "Does efficiency help banks survive and thrive during financial crises?" Journal of Banking \& Finance, vol. 106, no. 7, pp. $445-470,2019$.

[6] O. Badunenko and S. C. Kumbhakar, "Economies of scale, technical change and persistent and time-varying cost efficiency in Indian banking: do ownership, regulation and heterogeneity matter?" European Journal of Operational Research, vol. 260, no. 2, pp. 789-803, 2017.

[7] C. Curi, A. Lozano-Vivas, and V. Zelenyuk, "Foreign bank diversification and efficiency prior to and during the financial crisis: does one business model fit all," Journal of Banking \& Finance, vol. 61, no. 1, pp. 22-35, 2015.

[8] F. Mergaerts and R. Vander Vennet, "Business models and bank performance: a long-term perspective," Journal of Financial Stability, vol. 22, no. 2, pp. 57-75, 2016.

[9] M. M. Cornett, O. Erhemjamts, and H. Tehranian, "Greed or good deeds: an examination of the relation between corporate social responsibility and the financial performance of U.S. commercial banks around the financial crisis," Journal of Banking \& Finance, vol. 70, no. 9, pp. 137-159, 2016.

[10] A. Novak, D. Bennett, and T. Kliestik, "Product decisionmaking information systems, real-time sensor networks, and artificial intelligence-driven big data analytics in sustainable industry 4.0," Economics, Management, and Financial Markets, vol. 16, no. 2, pp. 62-72, 2021. 
[11] L. Laeven, R. Levine, and S. Michalopoulos, "Financial innovation and endogenous growth," Journal of Financial Intermediation, vol. 24, no. 1, pp. 1-24, 2015.

[12] S. Chen, "Economic growth, real estate climate and local debt risks: impulse and stress-testing," China Real Estate, vol. 21, no. 10, pp. 39-50, 2021.

[13] S. A. Olakojo, A. T. Onanuga, and O. T. Onanuga, "Cyclical fluctuations of economic growth and monetary policy in Nigeria: does fiscal policy also matter," Journal of Contemporary African Studies, vol. 39, no. 16, pp. 1-22, 2021.

[14] C. Liu, F. Guo, and J. Fu, "Political incentive, capital regulation and local bank credit supply," Journal Management World, vol. 10, no. 1, pp. 36-50, 2017.

[15] Y. Chen, S. Jin, and X. Wang, "Solvency contagion risk in the Chinese commercial banks' network," Physica A: Statistical Mechanics and Its Applications, vol. 580, no. 3, pp. 126-128, 2021.

[16] A. Tarchouna, B. Jarraya, and A. Bouri, "Do board characteristics and ownership structure matter for bank non-performing loans? Empirical evidence from US commercial banks," Journal of Management \& Governance, vol. 2021, pp. 1-40, 2021.

[17] R. Girshick, J. Donahue, T. Darrell, and J. Malik, "Regionbased convolutional networks for accurate object detection and segmentation," IEEE Transactions on Pattern Analysis and Machine Intelligence, vol. 38, no. 1, pp. 142-158, 2016.

[18] I. Andrievskaya and M. Semenova, "Does banking system transparency enhance bank competition? Cross-country evidence," Journal of Financial Stability, vol. 23, no. 9, pp. 33-50, 2016.

[19] M. Bouvard, P. Chaigneau, and A. D. Motta, "Transparency in the financial system: rollover risk and crises," The Journal of Finance, vol. 70, no. 4, pp. 1805-1837, 2015.

[20] P. De Araujo and K. I. Leyshon, "The impact of international information disclosure requirements on market discipline," Applied Economics, vol. 49, no. 10, pp. 954-971, 2016.

[21] B. Giner, A. Allini, and A. Zampella, "The value relevance of risk disclosure: an analysis of the banking sector," Accounting in Europe, vol. 17, no. 2, pp. 129-157, 2020.

[22] F. S. Hamid and N. M. Yunus, "Market discipline and bank risk taking: evidence from the east asian banking sector," East Asian Economic Review, vol. 21, no. 1, pp. 29-57, 2017.

[23] Ł. Kozłowski, "Cooperative banks, the internet and market discipline," Journal of Co-Operative Organization and Management, vol. 4, no. 2, pp. 76-84, 2016.

[24] L. Kuranchie-Pong, G. A. Bokpin, and C. Andoh, "Empirical evidence on disclosure and risk-taking of banks in Ghana," Journal of Financial Regulation and Compliance, vol. 24, no. 2, pp. 197-212, 2016.

[25] H. Li, H. Liu, A. Siganos, and M. Zhou, "Bank regulation, financial crisis, and the announcement effects of seasoned equity offerings of US commercial banks," Journal of Financial Stability, vol. 25, no. 8, pp. 37-46, 2016.

[26] H. A. Alaka, L. O. Oyedele, H. A. Owolabi et al., "Systematic review of bankruptcy prediction models: towards a framework for tool selection," Expert Systems with Applications, vol. 94, no. 4, pp. 164-184, 2018.

[27] E. I. Altman, M. Iwanicz-Drozdowska, E. K. Laitinen, and A. Suvas, "Financial distress prediction in an international context: a review and empirical analysis of altman's $Z$-score model," Journal of International Financial Management \& Accounting, vol. 28, no. 2, pp. 131-171, 2017.
[28] F. Barboza, H. Kimura, and E. Altman, "Machine learning models and bankruptcy prediction," Expert Systems with Applications, vol. 83, no. 9, pp. 405-417, 2017.

[29] C.-H. Chou, S.-C. Hsieh, and C.-J. Qiu, "Hybrid genetic algorithm and fuzzy clustering for bankruptcy prediction," Applied Soft Computing, vol. 56, no. 6, pp. 298-316, 2017.

[30] L. Cleofas-Sánchez, V. García, A. I. Marqués, and J. S. Sánchez, "Financial distress prediction using the hybrid associative memory with translation," Applied Soft Computing, vol. 44, no. 7, pp. 144-152, 2016.

[31] K. W. De Bock, "The best of two worlds: balancing model strength and comprehensibility in business failure prediction using spline-rule ensembles," Expert Systems with Applications, vol. 90, no. 12, pp. 23-39, 2017.

[32] X. Feng, Z. Xiao, B. Zhong, J. Qiu, and Y. Dong, "Dynamic ensemble classification for credit scoring using soft probability," Applied Soft Computing, vol. 65, no. 4, pp. 139-151, 2018.

[33] J. A. S. Lustosa Filho, A. M. P. Canuto, and R. H. N. Santiago, "Investigating the impact of selection criteria in dynamic ensemble selection methods," Expert Systems with Applications, vol. 106, pp. 141-153, 2018.

[34] V. García, A. I. Marqu'es, and J. S. Sanchez, “An insight into the experimental design for credit risk and corporate bankruptcy prediction systems," Journal of Intelligent Information Systems, vol. 44, no. 1, pp. 159-189, 2015.

[35] L. Guillaume, F. Nogueira, and C. K. Aridas, "Imbalancedlearn: a Python Toolbox to tackle the curse of imbalanced datasets in machine learning," Journal of Machine Learning Research, vol. 18, no. 17, pp. 1-5, 2017.

[36] G. Haixiang, L. Yijing, J. Shang, G. Mingyun, H. Yuanyue, and G. Bing, "Learning from class-imbalanced data: review of methods and applications," Expert Systems with Applications, vol. 73, no. 4, pp. 220-239, 2017.

[37] N. Nikolaou, N. Edakunni, M. Kull, P. Flach, and G. Brown, "Cost-sensitive boosting algorithms: do we really need them," Machine Learning, vol. 104, no. 2-3, pp. 359-384, 2016.

[38] A. Roy, R. M. O. Cruz, R. Sabourin, and G. D. C. Cavalcanti, "A study on combining dynamic selection and data preprocessing for imbalance learning," Neurocomputing, vol. 286, no. 4, pp. 179-192, 2018.

[39] D. Veganzones and E. Séverin, "An investigation of bankruptcy prediction in imbalanced datasets," Decision Support Systems, vol. 112, no. 8, pp. 111-124, 2018.

[40] Y. Zelenkov, E. Fedorova, and D. Chekrizov, “Two-step classification method based on genetic algorithm for bankruptcy forecasting," Expert Systems with Applications, vol. 88, no. 12, pp. 393-401, 2017. 